\title{
Neuroendocrine carcinomas of the larynx: what do the different histologic types really mean?
}

\author{
Kenneth O. Devaney • Alfio Ferlito • Alessandra Rinaldo
}

Received: 12 June 2010 / Accepted: 14 June 2010 / Published online: 30 June 2010

(C) Springer-Verlag 2010

A century ago, it was a significant accomplishment to distinguish between laryngeal epithelial malignancies (carcinomas), mesenchymal malignancies (sarcomas) and hematopoietic malignancies (lymphomas). A great deal has changed since that time; while the vast majority of laryngeal malignancies will prove to be carcinomas, the family of carcinomas has grown to encompass an impressively large array of different pathologically defined entities.

One subset of epithelial malignancies of the larynx that can give rise to some confusion is one of the more uncommon subsets, the group of neuroendocrine carcinomas of the larynx. To be clear, this group - to be discussed herecomprises the epithelial-derived neuroendocrine tumors, and so excludes the neurally derived tumors (such as paraganglioma, neuroblastoma, Ewing's sarcoma, and primitive neuroectodermal tumor). As such, this group of epithelial neuroendocrine carcinomas of the larynx encompasses four discrete pathologically defined entities: carcinoid tumor, atypical carcinoid tumor, small cell neuroendocrine carcinoma, and large cell neuroendocrine carcinoma (as well, combined tumors - such as atypical carcinoid tumors, small cell and large cell neuroendocrine carcinomas-may be

This paper was written by members of the International Head and Neck Scientific Group (http://www.IHNSG.com).

K. O. Devaney

Department of Pathology,

Allegiance Health, Jackson, MI, USA

A. Ferlito $(\varangle) \cdot$ A. Rinaldo

Department of Surgical Sciences, ENT Clinic,

University of Udine, Azienda Ospedaliero-Universitaria,

Piazzale S. Maria della Misericordia, 33100 Udine, Italy

e-mail: a.ferlito@uniud.it encountered, but are not further discussed here in light of their extreme rarity) [1-4].

While these four tumor types are marked by widely differing light microscopic appearances, they are united by the presence of some combination of positivity by immunohistochemistry with antibodies including cytokeratin, chromogranin, synaptophysin, CD56, CD57, neuron-specific enolase, serotonin, somatostatin, bombesin, and protein gene product 9.5 [5].

\section{Laryngeal carcinoid tumors}

The laryngeal carcinoid tumors are rare tumors. By light microscopy, they resemble the more commonly encountered carcinoid tumors of the appendix or lung, with nests and ribbons of uniform bland epithelioid cells by routine light microscopy; neither mitotic activity nor necrosis is a feature of the carcinoid tumors. There is a distinct male predominance, centered in middle-age; while distant metastases can develop over the course of extended follow-up, the 5 -year survival rate was reported to be $48.7 \%$ in one large series [6]. It is possible that the low survival rate may be due to the erroneous inclusion of several cases of atypical carcinoid tumor as typical carcinoids [7]. However, it is true that carcinoid tumors are more aggressive than was previously believed, and ultimately may metastasize in about a third of cases.

\section{Laryngeal atypical carcinoid tumors}

Atypical carcinoid tumors maintain the light microscopic architectural features of the carcinoid tumors, with prominent arrangement of tumor cells into cords and ribbons; 
however, the individual tumor cells of an atypical carcinoid tumor are more pleomorphic, with areas of necrosis and mitotic activity. These tumors are seen mostly in middleaged male patients, like carcinoid tumors, but unlike carcinoid tumors frequently present with concurrent regional node metastases. The 5-year survival for atypical carcinoid tumors was $46.7 \%$ [6].

\section{Laryngeal small cell neuroendocrine carcinomas}

As with pulmonary small cell carcinomas (or, for that matter, small cell carcinomas arising in other uncommon locales, such as the bladder or the colon), laryngeal small cell carcinomas are-by light microscopy-composed of sheets, cords and ribbons of pleomorphic hyperchromatic oval to round tumor cells distinguished by a very limited quantity of accompanying cytoplasm; both necrosis and mitotic activity are prominent features of small cell neuroendocrine carcinomas. As with the two preceding tumor types, these tumors show a male predominance, developing in a patient population slightly older than the populations with carcinoid tumors or atypical carcinoid tumors. Very few patients with laryngeal small cell neuroendocrine carcinomas survive for 5 years after initial diagnosis. The survival rates are similar to those for small cell lung cancer [8] and do not correlate with the tumor size [9].

\section{Laryngeal large cell neuroendocrine carcinomas}

The large cell variant is the rarest neuroendocrine carcinoma of the larynx. Before the widespread use of immunohistochemical studies, these tumors were probably grouped with the undifferentiated/poorly differentiated carcinomas of the larynx. Once it became apparent that these tumorsmarked by light microscopy by a population of cells which were larger, with more abundant cytoplasm, than small cell carcinoma cells-expressed neuroendocrine markers, they were segregated from the remainder of the poorly differentiated carcinomas as large cell neuroendocrine carcinomas [10-13]. These are principally tumors of older men, with a dismal prognosis.

\section{And so, what is the best classification scheme?}

As a function of the clinical course of disease itself, it appears at the present time as though there are three groups of laryngeal neuroendocrine tumors: (1) the laryngeal carcinoid tumors, which - while not benign - appear to be less aggressive tumors than the other laryngeal neuroendocrine carcinomas; (2) the laryngeal atypical carcinoid tumors, which the patient has approximately a 50:50 chance of surviving; and (3) the laryngeal small cell neuroendocrine carcinomas and large cell neuroendocrine carcinomas, which in the vast majority of instances will prove fatal to the patient.

There might be two reasons to separate the two elements of the third group - one, if it were deemed useful to maintain the distinction between the two (grounded in light microscopy) as a reminder that there may in the future be differences between small cell and large cell neuroendocrine carcinomas (as, for example, with regard to diagnosis, or treatment) that would lead to differences in the course of disease; or, two, if the treatment for the two tumors is presently different-which clearly would demand that the distinction be maintained.

This is not a debate without precedent in any other sites; the lung also gives rise to neuroendocrine carcinomas, and both four-tiered and three-tiered classification schemes are presently employed there to separate the various types of pulmonary neuroendocrine malignancies $[14,15]$.

At present, the rarity of laryngeal neuroendocrine carcinomas makes it difficult to stratify patients-particularly those in the three more aggressive groups-into different meaningful treatment groups. It is for this reason that we suggest that head and neck pathologists and clinicians take a page from the pulmonary literature and segregate laryngeal neuroendocrine tumors into three types: grade I neuroendocrine carcinoma (the carcinoid tumors), grade II neuroendocrine carcinoma (the atypical carcinoids), and grade III neuroendocrine carcinoma (encompassing two subtypes: the small cell neuroendocrine carcinomas, and the large cell neuroendocrine carcinomas [14-16]). Such a classification scheme serves the twin purposes of creating divisions that memorialize the three generally different behaviors of this spectrum of tumor types, and of recognizing (through the use of the two subtypes of the grade III neuroendocrine carcinomas) the existence of two different light microscopic patterns of tumor with similar clinical courses (that is, the small cell and large cell neuroendocrine carcinomas, considered together as grade III tumors).

\section{References}

1. Milroy CM, Robinson PJ, Grant HR (1989) Primary composite squamous cell carcinoma and large cell neuroendocrine carcinoma of the hypopharynx. J Laryngol Otol 103:1093-1096

2. Jaiswal VR, Hoang MP (2004) Primary combined squamous and small cell carcinoma of the larynx: a case report and review of the literature. Arch Pathol Lab Med 128:1279-1282

3. Barbeaux A, Duck L, Weynand B, Desuter G, Hamoir M, Gregoire V, Baurain JF, Machiels JP (2006) Primary combined squamous and small cell carcinoma of the larynx: report of two cases and discussion of treatment modalities. Eur Arch Otorhinolaryngol 263:786-790 
4. Davies-Husband CR, Montgomery P, Premachandra D, Hellquist H (2010) Primary, combined, atypical carcinoid and squamous cell carcinoma of the larynx: a new variety of composite tumour. J Laryngol Otol 124:226-229

5. Ferlito A, Silver CE, Bradford CR, Rinaldo A (2009) Neuroendocrine neoplasms of the larynx: an overview. Head Neck 31:16341646

6. Soga J (2003) Carcinoids and their variant endocrinomas. An analysis of 11842 reported cases. J Exp Clin Cancer Res 22:517-530

7. Ferlito A, Devaney KO, Rinaldo A (2006) Neuroendocrine neoplasms of the larynx: advances in identification, understanding, and management. Oral Oncol 42:770-788

8. Ferlito A, Rinaldo A (2008) Primary and secondary small cell neuroendocrine carcinoma of the larynx: a review. Head Neck 30:518-524

9. Gnepp DR (1991) Small cell neuroendocrine carcinoma of the larynx. A critical review of the literature. ORL J Otorhinolaryngol Relat Spec 53:210-219

10. Trabka-Zawicki P, Składzień J, Zawiliński J, Wierzchowski W (2002) Diagnostic difficulties in neuroendocrine carcinoma of the larynx. Otolaryngol Pol 56:433-435 (article in Polish)
11. Chung JH, Lee SS, Shim YS, Kim SY, Nam SY, Kim DH, Cho KJ (2004) A study of moderately differentiated neuroendocrine carcinomas of the larynx and an examination of non-neoplastic larynx tissue for neuroendocrine cells. Laryngoscope 114:1264-1270

12. Greene L, Brundage W, Cooper K (2005) Large cell neuroendocrine carcinoma of the larynx: a case report and a review of the classification of this neoplasm. J Clin Pathol 58:658-661

13. Hallaoui Y, El Kohen A, Sefiani S, Benchekroun L, Jazouli N, Kzadri M (2004) Laryngeal neuroendocrine carcinoma: a case report. Rev Laryngol Otol Rhinol (Bord) 125:229-232 (article in French)

14. Brambilla E, Travis WD, Colby TV, Corrin B, Shimosato Y (2001) The new World Health Organization classification of lung tumours. Eur Respir J 18:1059-1068

15. Höfler H (1997) Neuroendokrine Tumoren der Lunge. Verh Dtsch Ges Pathol 81:118-124

16. Mills SE (2002) Neuroectodermal neoplasms of the head and neck with emphasis on neuroendocrine carcinomas. Mod Pathol 15:264-278 